\title{
Contribución al estudio de la blastomicosis
}

\author{
POR SAMUEL LOZADA BENAVENTE \\ Interno de los Hospitales
}
A la memorla de mi padre, don Hermbce- NES LozAdA.
A mis maestros, los doclores EDMUNDo Escomel y Max. Gonzales Olaecinea.

El estudio de la Blastomicosis ha adquirido importancia, en razón de que en estos últimos tiempos se ha señalado la gran difusión de la dolencia, pues, ubicada su localización geográfica en el corazón de la América tropical, ofrece en Bolivia, Brasil y Perú el mayor número de ejemplares clínicos, y es tanto más importante su conocimiento para nosotros, en razón de su caracterización que ha dado fundamento para separar del grupo de úlceras tropicales, conocidas con el nombre vulgar de Espundia, un conjunto de casos clínicos en los que no es hallaba la leishmania productora. y en los cuales el Dr. E. Escomel encontró en 1914, por primeráa vez en el Perú, un hongo del género Blastomiceto

Desde esa época se inicia el estudio de la Blastomicosis en la régión occidental de la América del Sur (Perú y Bolivia), sé caracteriza perfectamente la sintomatología de la enfermedad. la hiología del gérmen productor. las modalidades anatomopatológicas y se explica, por último, el porqué no era eficaz en todos los casos de espundia la terapia antimonial, reconocida como específica por los médicos brazileros en la leishmaniasis; terapéutica que en otros casos se detenía en la mejoría, en el semi éxito terapéutico, en virtud de que se implantaba en pacientes que ofrecían pricesos mixtos: leishmanio-blastomicósicos. 
Estos estudios iniciados por el Dr. Escomel y hasta ahora únicamente continuados por él, en el Perú, fueron bien pronto confirmados por el Dr. Nestor Morales Villazon de la Paz (Bolivia) y por el Prof. TERRa de Río de Janeiro (Brasil), evidenciándose de esta manera la exactitud de las primeras investigaciones hechas en la América del Sur por Lutz, Splendore, Sommer y otras. Posteriormente se han señalado casos en el Uruguay y Paraguay.

No hay duda que en la literatura médica americana, hay descripciones que corresponden a la entidad morbosa que tratamos. Como prueba de ello trascribiremos algunos párrafos del trabajo que el Dr. Sagarnaga ex-decano de la Facultad de Medicina de La $\mathrm{Paz}$ (Bolivia) presentó al Congreso Médico Latino-Americano, reunido en Santiago de Chile el 24 de diciembre de 1906:

«Mantengo, dice: la opinión que tengo formada sobre la Espundia, basada en mis observaciones clínicas que son bastante numerosas, como de la consulta que he hecho a todos los autores que se ocupan de la materia y afirmo que la Espundia del Noroeste de Bolivia no es otra cosa que la afección descrita con el nombre de fagedenismo de los países cálicios o mejor con el nombre de úlcera fagedénica, enfermedad que como hemos visto es engendrada por el bacilo de Vincent».

Igualmente, en Febrero de 1906, el Dr. Ballivian Otero en un informe que presentó al Gobierno de Bolivia, sobre el territorie de Colonias del noroeste, en donde desempeñaba el cargo de Médico y Cirujano de la Delegación Nacional dice que piensa, en oposición al Dr. Sagarnaga, que *la Espundia es una entidad mórbida completamente diferente de la úlcera fagedénica de los países cálidos, pues, tiene caracteres específicos que le permiten individualizarla .

Nosotros estudiaremos la Blastomicosis, hasándonos en les casos que hemos observado durante nuestra estadía en La Paz (Bolivia).

\section{Distribucion geOGRAFICA DE LA bLASTOMICOSIS}

El Dr. Sagarnaga en el tratiajo ya citado que presentó al Congreso Médico Latino Americano reunido en Santiago de Chile, el 24 de diciemhre de 1906, divide el territorio de Bolivia en tres rgiones:

1.-Región de la Costa, al oeste de los Andes;

2. - Región Montañosa o de la sierra, comprendida entre la. Cordillera real y' el exterior:

3."-Región de los bosques, que se extiende desde la vertiente oriental de la Cordillera real hasta las fronteras con el Brazil, el 
Perú, la Argentina y el Paraguay, y en la cual se localiza hoy día, la cuna de muchas enfermedades tropicales de la América del Sur y muy. especialmente la blastomicosis.

En el trabajo presentado por el distinguido médico toliviano Dr Nestor Morales. Villazon, sobre la Blastomicosis, al ocuparse de la distribución geográfica señala como lugares de predilección y de máxima frecuencia de la enfermedad, a las regiones de NordYungas y Sud-Yungas e Inquisive, en el departamento de La Paz; a la cuenca de los principales rías en el territorio de Colonias, a una parte del Departamento del Beni y a otra de los ciepartamentcs de Santa Cruz y Cochabamba.

Pues bien, por las historias clínices que presento y por los numerosos datos a este respecto que he rẹcogido, hemcs comprobado que el mayor número de enfermos vienen de las regiones que señala. El Dr. Casto Orihuela, al ocuparse en 1919 de la Geografía Médica de Bolivia, coloca las localidades ya enumeradas entre las que son de clima cálido,pues dice: «Este grupo lo constituyen los climas semitropicales y tropicales; los primeros en una extensión de 152,785,48 Kilómetros cuadrados, abarcan en el departamento de La Paz, Jas provincias de Caupolican, Loaiza, Nord y Sud-Yungas; en el departamento de Chuquisaca, la de. Tomina; en el departamento de Cochabamba, las de Chapere; Arque y Capinota; en el departamento de Santa Cruz, Valle Grande y Cercado. Los segundos alcanzan un tọtal de 383,550.28 Kilómetros cuadrados, comprenden en el departamento del Beni las provincias de Yacuma, Noca, Diez' y Cercado; en el departamento de Santa Cruz las de Velasco, Chiquitọs y Cordillera; en el departamento de Chuquisaca, la de Acero; en el territorio de Colonias, la delegación de los ríos Beni, Madre de Dios, Acre, Orton; en el departamento de Tarija, la Colonia del Chaco Boreal. En estas regiones la temperatura está comprendida entre 21 y 27 grados*. Tal es la distribución geográfica de la Blastomicosis en Bolivia.

En el Perú, según el D.r. Escomer, asciende hacia el río Marañón y el río Ucayali, pero dismmuye el número de cașos de Blastomicosis, cuanto más se aleja del Madre de Dios: para ser reemplazado por las úlceras Leishmaniásicas.

Lutz, Rabello, Machado, Terra y otros, Greco y.WerNICKE, han dado a conocer la distribución geográfica en el Brasil y Argentina respectivamente. 


\section{DESCRIPCION CLINICA}

Para el estudio de la enfermedad que nos ocupa consideraremos tres períodos: período primario, período secundario, período terciario y podríamos añadir un cuarto período, el período caquéctico.

Periodo primario. - El periodo primario, o período inicial como lo llama el Dr. Escomel, está caracterizado, por la aparición de un chancro, chancro blastomicósico de Escomel, que puede tener lugar en la pierna, de preferencia en su tercio inferior, o en el antebrazo, sobre su porción dorsal, y algunas veces, aunque raras, en el lóbulo de la oreja.

No nos ha sido posible observar la lesión en este período, porque rara vez se presentan los enfermos en La Paz, para hacerse curar de una lesión que la mayoría juzga sin importancia y porque cura, tal vez expontaneamente, según se deduce de la anamnesis hecha a un gran numero de estos enfermos, pues refieren que la mencionada ulceración cura con las medicaciones mas extravagantes, sin hacer uso, por lo menos en todos los casos que nos ha sido posible observar en el Lazareto de La Paz (Bolivia), de la cauterización. I que la curación se produce, podemos afirmarlo, ya que nos ha sido posible comprobar las cicatrices, que con justa razón muchos de ellos consideran como la causa de su enfermedad. Las cicatrices en unos son lizas, despigmentadas, avanzando la despigmentación una regulăr extensión; en otros, los bordes de la cicatriz son verrugosos.

Al describir su lesión inicial, casi todos ellos coinciden en la forma como comienza; principia por un granito muy prurriginoso, que el enfermo convierte por el rascado en una ulceración, que sangra con mucha facilidad y que después de una evolución variable, para cada enfermo, pues en unos es de cuatro meses, en otros es de ocho meses, de un año o más, de cura, lo cual creemos que no tiene nada de particular, dado que según el individuo asi son los medios que emplea para su curación. Por otra parte, las infecciones secundarias complican el proceso reparador y hacen más larga su evolución.

En el Lazareto de La Paz, sólo ingresan enfermos que en sus mayor parte son de Nord y Sud Yungas, cuando las lesiones han tomado la cara o la garganta después de 5 ó 6 años de enfermedad; pero todos ellos, sin una sola excepción, en los casos por mí observados, al interrogarles sobre el pasado mórbido, acusan siempre una herida, ya sea de la piema, del brazo, de la oreja, del cuello. de los dedos, etc., etc., siempre de las partes descubiertas y nun- 

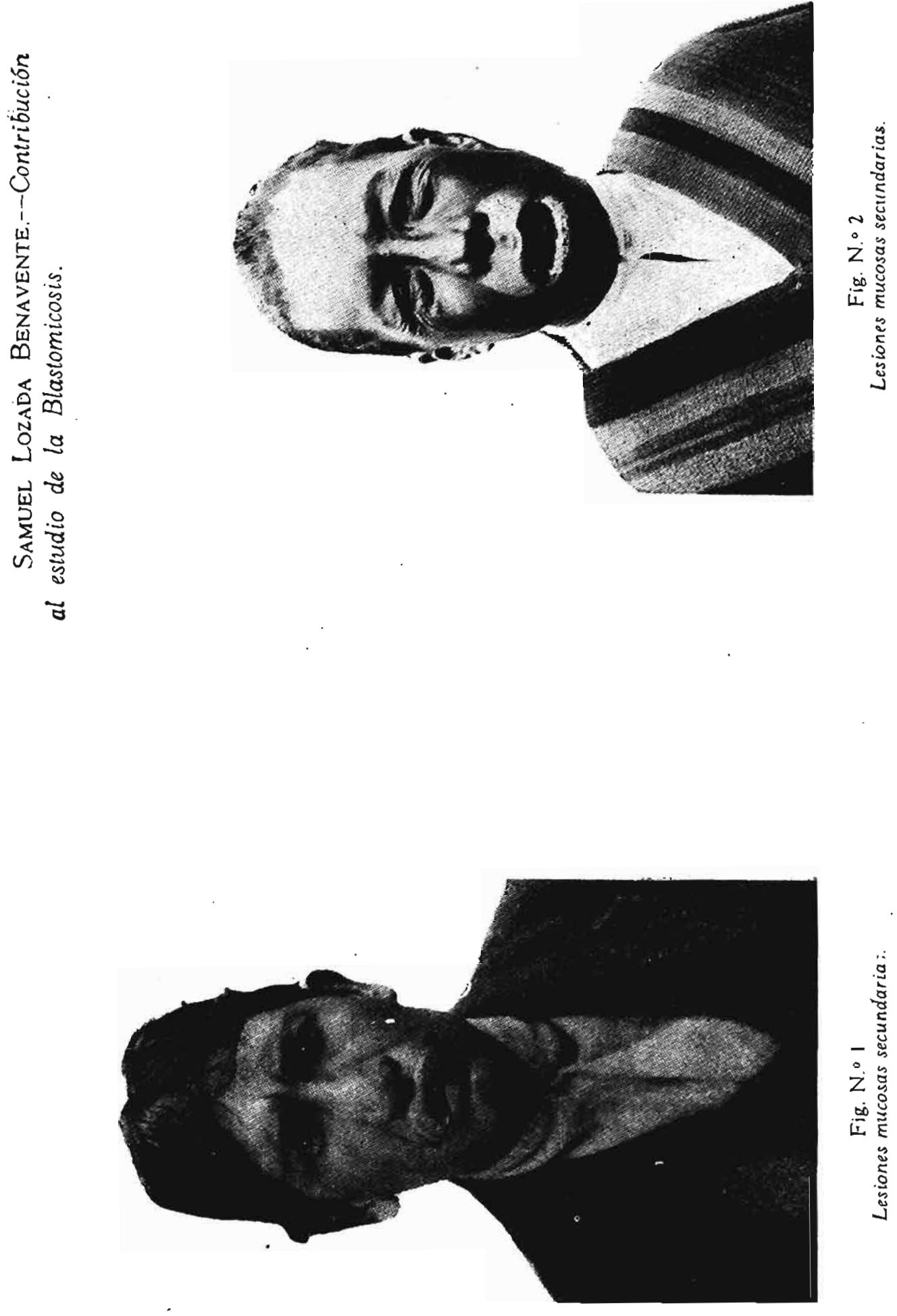
ca de la espalda, del abdomen, de las nalgas, etc., etc. Cuando éstas se presentan son debidas a autoinoculaciones producidas por el mismo enfermo con el rascado, todo lo cual viene a comprobar lo dicho por EsCOMEL.

Es de notar que esta enfermedad hace la mayor parte de sus víctimas entre la gente que trabaja en el caucho o el monte, y que tiene por costumbre estar con los pies descalzos o con abarcas, y que son muy pocos los atacados entre la gente que usa calzado y gusta de los cuidados higiénicos.

De modo que podríamos decir que la lesión empieza por la posible picadura de un insecto que ataca las partes descubiertas del cuerpo, sin que podamos caracterizarlo, pues, unos dicen que es un mosquito, otros una mosca, una arañita de pequeñas dimensiones, etc., etc.; que después se levanta una vesícula que se trasforma en pápula de contenido purulento y muy prurriginoso, que se ulcera por el rascado y evoluciona de modo variable, pero con tendencia a la curación expontánea.

Periodo secundario.- No puede afirmarse de manera precisa, qué tiempo transcurre entre la lesión inicial y la aparición de las lesiones secundarias, porque en unos se presenta a los dos años, en otros al año y en algunos, como en el enfermo de la Fig. No. 1 a los dos meses de cicatrizada la lesión inicial, aparecen las lesiones nasales.

En algunos enfermos desde el principio invade el paladar membranoso, como en el enfermo de Tumisi (Fig. No. 2). Y es progresivamente que invade la mucosa de los carrillos, la cara mucosa de ambos labios, para comenzar a dibujarse, después en el borde libre de estos. En el enfermo a que acabo de hacer mención, apesar de que la úvula, pilares, amígdalas, paladar membranoso, mucosa de los carrillos, de los labios, estaban invadidos, las fosas nasales, fundándonos en el examen rinoscópico anterior, no tenían nada de anormal y funcionalmente el enfermo no sentía ninguna molestia; en otros casos cuyo tipo es el enfermo de la Fig. No. 3, la lesión empezó en el lado derecho del labio superior, la ulceración invadió casi la totalidad, de ambos labios, avanzó sobre la muicosa gingival de los dientes incisivos, caninos y primeros molares, especialmente del maxilar superior, que estaba destruído en gran parte, dejando las raíces dentarias al descubierto y atacadas de periostitis alveolo-dentaria, a tal punto que el enfermo al hablar, movía los dientes a manera de una cortina. El velo del paladar, úvula, amígdalas, pilares, etc., estaban sanos.

En otros enfermos las lesiones cutáneas y mucosas se presentan al mismo tiempo, tal es el enfermo de la Fig. No. 4, en el que 
las lesiones empezaron por un granito en el labio superior, que invadió después la nariz, tomó después la comizura labial izquierda, avanzando por ambos labios; al mismo tiempo se presentaban las lesiones mucosas.

Por último, en otros enfermos, uno de cuyos tipos es el enfermo de la Fig. No. 5, las lesiones secundarias aparecen en la parte anterior de la nariz, poco después invaden ambas mejillas, las fosas nasales, ulceran y casi destruyen los cornetes y determinan proliferación intensa en los tejidos colindantes, que hacen muy difícil la respiración nasal.En este caso después de algunos meses apareció una ulceración de forma ovaliforme en el paladar, que progresivamente siguió avanzanclo hacia la porción inferior.

Es digno hacer notar que las ulceraciones de la garganta, no son dolorosas, a tal punto que muchos enfermos, solo se dan cuenta, porque al hacer el examen se lo decíamos, no sin cierta sorpresa para ellos; en otros, las lesiones son muy poco dolorosas, una ligera molestia en el acto de deglutir; a todos les hemos visto con excelente apetito, ingerir sus alimentos del almuerzo y de la comida durante nuestras visitas de la mañana y de la tarde, sin que dibujaran en sus semblantes la menor molestia; al ser interrogados nos han respondido la mayoría, que comían como si no tuvieran lesión alguna en su garganta.

Lesiones cutáneas: el aspecto de las lesiones externas es el siguiente: es una ulceración de bordes perfectamente limitables, al rededor de los cuales la piel está infiltrada y de un color violaceo; el fondo de la ulceración de color amarillorojizo, con uno que otro foquito hemorrágico, está cubierto de granulaciones, presentando también costras amarillentas, que al desprenderse hacen sangrar la herida, que después resume una serosidad, que al concretarse forma la costra amarilla; cn los sitios en que la infiltración es mayor y el color violáceo más intenso, empieza la destrucción del tejido superficial, que trae como consecuencia la producción de una secreción que da lugar a la formación de una costra, débajo de la cual hay pequeños focos.supurativos. La ulceración, sin tratamiento, avanza en profundidad, y por la union con focos colindantes, iguales, gana también en superficie.

Es digno de hacer notar que estos enfermos que tienen cubiertas sus ulceraciones con pañuelos y trapos inmundos, que las tocan con manos desprovistas de la más elemental higiene, no ofrecen mayormente las consecuencias de las infecciones secundarias, pues, en ninguna de estas ulceraciones se encuentre una verdadera supuración. 


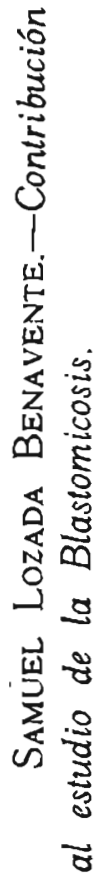
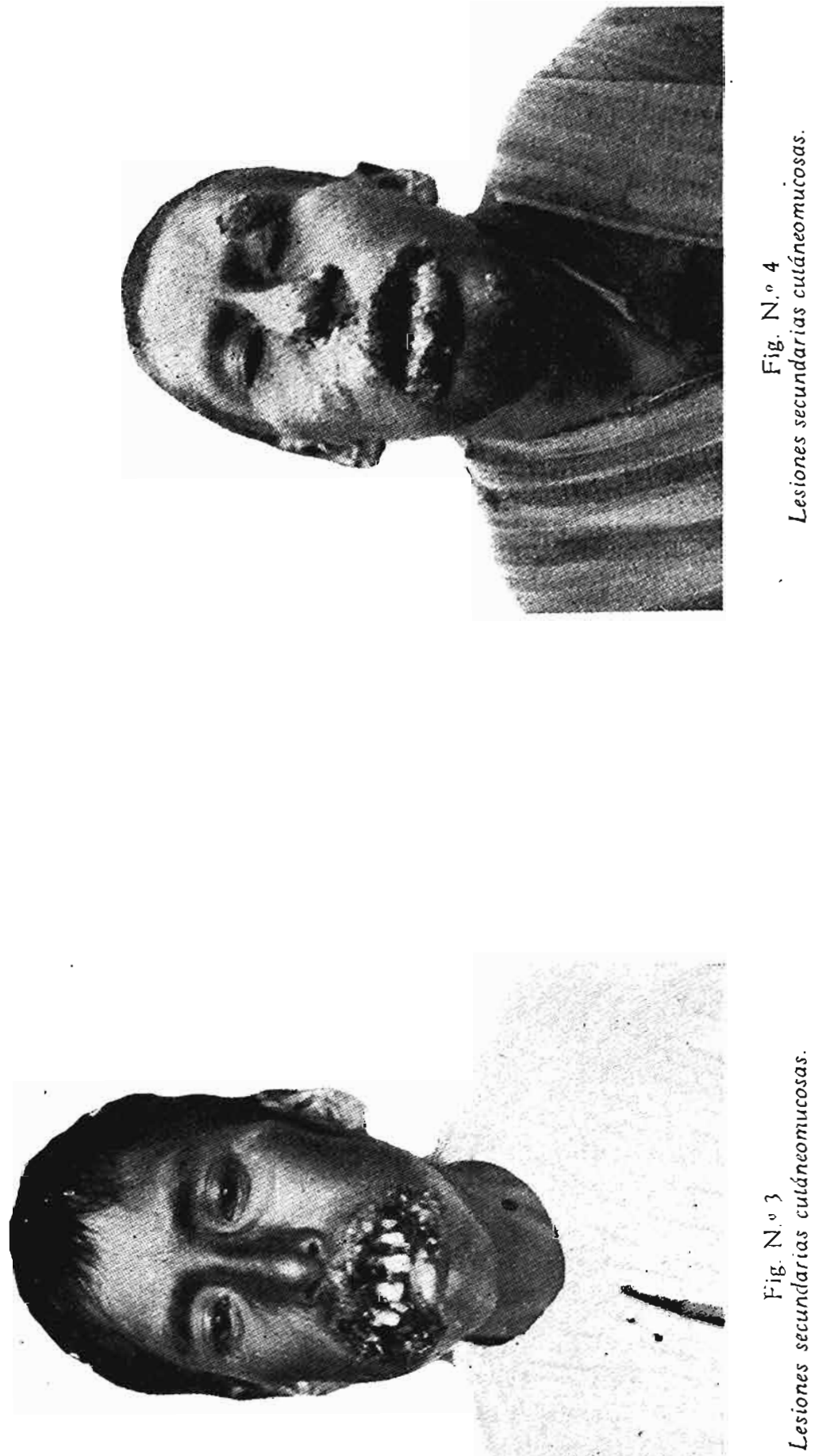
En todas las partes donde se implantan las ulceraciones, que frecuentemente es en los labios, nariz, mejillas, etc., el tejido colindante se hiperpigmenta, se infiltra y adquiere un grosor bastante pronunciado. Las ulceraciones, casi todas, son de un color rosado, ligeramente pálido y sangran con facilidad; cuando la ulceración invade el labio, lo que es muy frecuente, éste al cabo de algún tiempo pierde su elasticidad, sus movimientos son más difíciles, aumenta el doble, el triple y aún el cuádruplo de su volumen primitivo, dando a la fisonomía de estos enfermos un aspecto repelente y humillante y. si como siempre sucede, van acompañadas de lesiones externas de la parte anterior de la nariz, fácil es darse cuenta del aspecto que presentan. Estos enfermos dicen que experimentan la sensación como ade gusanos" que corroen su herida.

En los enfermos en quienes las fosas nasales están atacadas, se ven los cornetes hipertrofiados y cubiertas de costras amarillentas, que al desprenderse dejan al descubierto una ulceración en cuyos bordes la mucosa está engrosada, llegando la hipertrofia de los cornetes y la propagación blastomicósica por el resto de la mucosa, a dificultar primero y anular después la respiración nasal. Hemos visto un enfermo en quien su conducto nasal estaba tan obstruido, que con dificultad podíamos pasar un estilete, que nos hacía percibir una sensación de dureza. De la invasión de las fosa nasales se da cuenta el enfermo por la dificultid respiratoria, por la siquedad nasal, por la sensación de cuerpo extraño que producen las costras, que cuando vienen al exterior, están mezcladas con un po co de sangre.

Las úlceras blastomicósicas de sede nasal, sangran con facilidad y en'su evolución progresiva destruyen el tabique nasal, dejando convertida la parte anterior en uriu amplia y única cavidad; en algunos casos, por encontrarse la parte anterior de la nariz sin sosten y hastante infiltrada, cae sobre el labio superior. La olfación está conservadú.

Lesiones inucosas: estas lesioncs casi siempre empiezan por el velo del paladar (cuando no han sido propagación de las fosas nasales), por granulaciones que, según el decir de los eníermos, foco después se ulceran, teniendo especial tendencia de progresar hacia la. laringe y muy poco hacia la bóveda palatina; después invaden los pilares, las amígdalas, la úvula, la parte superior de la pared posterior de la faringe, a tal punto que el aspecto anatómico normal desaparece. En algunos casos, más que en otros, se nota un surco vertical que, como pásaba en los enfermos de las Figs. Nos. 6 y 1, para hacer mención de los casos típicos, se inicia desde el 
medio del paladar óseo, llegando hasta el fondo de la garganta, el cual está cruzado por otro, de forma irregular, constituyendo lo que Escomel describiera por primera vez con el nombre de cruz palatina de la Espundia, y que después ha demostrado que pertenece a la Blastomicosis. En el fondo de este surco hay una sanies purulenta mezclada con saliva.

En otros enfermos, tal como el de la Fig. No. 5, la ulceración mucosa asienta en el paladar membranoso y está cubierta de botones carnosos, entre los que sobresalen algunos por sus mayores dimensiones; entre botón y botón hay una capa medio purulenta, cuya separación con el alambre de platino es fácil y donde precisamente se encuentra el mejor material para los cultivos y exámenes microscópicos; los bordes de esta ulceración son perfectamente marcados en el sentido longitudinal; el anterior, está rodeado de una aureola rojo-carmesí, por la mucosa colindante; el borde posterior: pilares, amígdalas, parte superior de la faringe, etc., está invadido por el proceso ulceroso, quedando la úvula convertida en un muñón lleno de surcos y botonoso, que se encuentra adherido a la porción superior de la pared posterior de la färinge.

Durante este período los enfermos no han sufrido gran desnutrición; conservan el apetito; el estado general es tueno; sintiéndose molestos únicamente por la abundante salivación, que, segun nos decían, aparece desde que se inician las lesiones mucosas, llegando en algunos enfermos a convertirse en un síntoma mortificante, en razón que al hablar esparcen la saliva a su alrededor. En el enfermo de la Fig. No. 6 el hecho había tomado tal intensidad que tenía que dormir en decúbito lateral izquierdo, para dejar fluir la saliva que salía por una fisura que tenía en el labio inferior y mojaba su almohada; nos refería que cuando dormía, e involuntariamente se colocaba de espaldas, despertaba al momento, con un acceso de tos, por la saliva que lo quería ahogar.

La rinitis hipertrófica, anulando la respiración nasal, obliga al enfermo a respirar por la boca, presentándose al cabo de poco tiempo una bronquitis crónica exacerbada por cualquier cambio de temperatura, como pasó con el enfermo de la Fig. No. 6; bronquitis que vimos curar luego que cicatrizadas sus lesiones se restablecib la respiración nasal, por medio de una intervención quirúrgica practicada con magníficos resultados, por el hábil cirujano Dr. DANIEL Bilbao.

En resumen: ulceración botonosa pruriginosa, de bordes engrosados, de tejido colindante infiltrado, recubierta de costras amarillentas que sangran con facilidad, son las características de las le- 

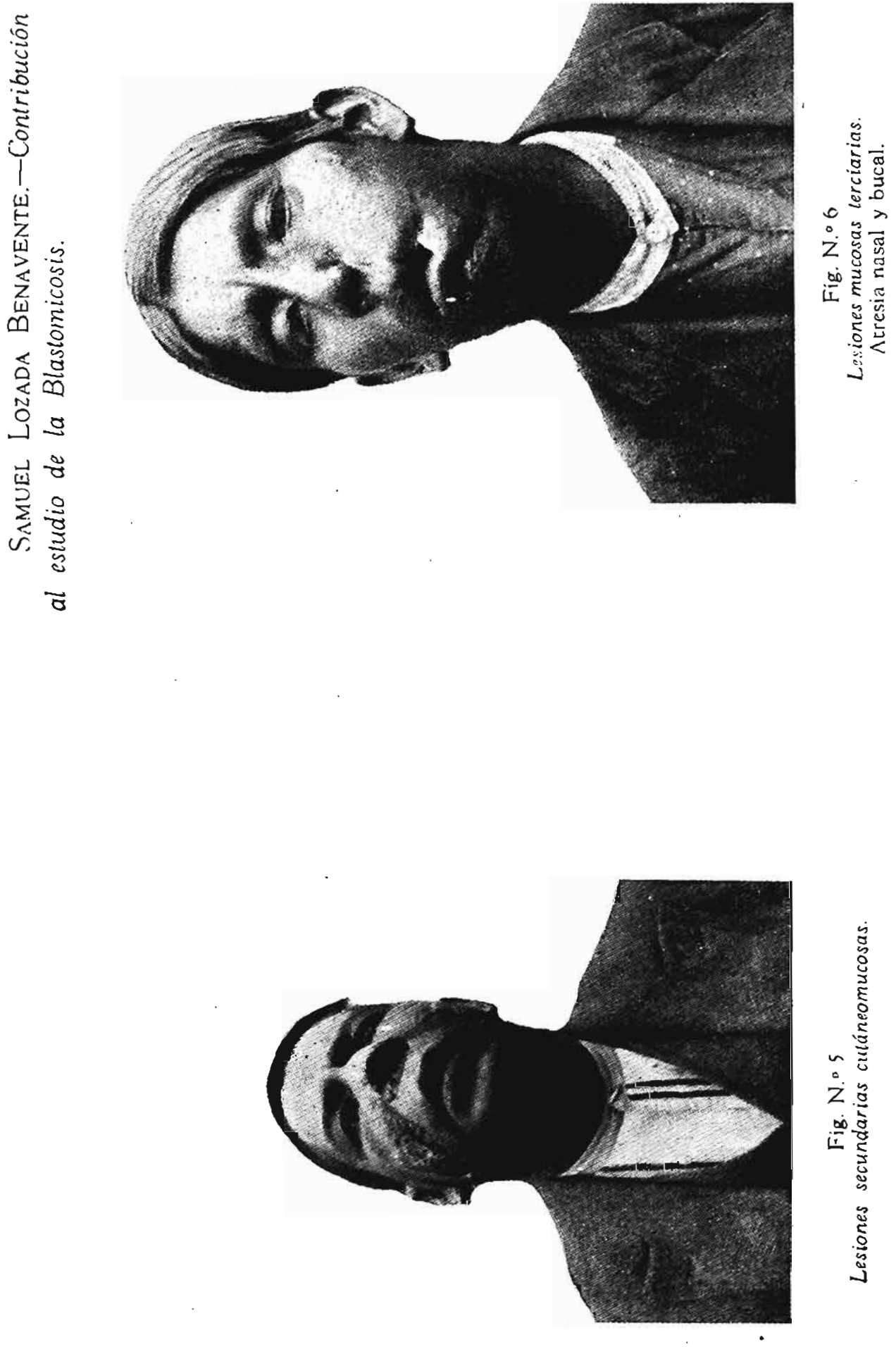
siones cutáneas de la Blastomicosis. Las lesiones mucosas cuando radican en el paladar membranoso, son de propagacion descendente, ofrecen la cruz platina y sialorrea; cuando las lesiones asientan en la mucosa nasal, detetminan rinitis hipertrófica ulcerativa. El apetito siempre está conservado; el estado general es bueno. Tales son las lesiones que caracterizan el segundo período de la Blastomicosis.

Tercer periodo.-En este período las lesiones, que tienen algunos años de evolución, están implantadas en organismos desgastados por la misma enfermedad y también por el estado de miseria en que se encuentran; de todas partes son repelidos por el fantasma del contagio y el aspecto que presentan, hasta que al fin buscan refugio en un hospital o lazareto.

En estos individuos, las ulceraciones han conservado su aspecto botonoso, pero ya su coloración es pálida, marchita, de un color blanco, muy pálidamente teñido de rosado, en algunos puntos; las ulceraciones ya no sangran con facilidad, como las del segundo período, está como anemiada la región vecina a las ulceraciones; ya no la recubren esas costras amarillentas que vimos en el segundo período, ahora están recubiertas de una secreción brillante, que le da un aspecto plateado a la ulceración y que a la manera de barniz cubre toda su superficie; tal es, entre otros muchos, el aspecto del enfermo representado por la Fig. No. 7. cuya enfermedad data poco más o menos de 11 años; en él los bordes de la ulceración son verdaderamente callosos y han invadido el labio inferior, haciendo constar que esta última lesión es propagación de las lesiones que primero tuvo en la mucosa; en otros enfermos, tal como el de la Fig. No. 8, las lesiones tienen lugar en el labio superior, lo destruyen en una gran parte, invaden la nariz, y, siguiendo toda la evolución que hemos apuntado en el períado secundario, destruyen los cornetes, toda la parte cartilaginosa de la nariz, etc., quedando un orificio de forma irregular por donde imperfectamente se verifica la respiración nasal; ese enfermo tenía en el ojo derecho un ectropión del párpado inferior, que desviaba el curso normal de las lágrimas hacia el conducto lácrimo-nasal, por la retracción de los tejidos que estaban ulcerados; este ectropion daba lugar a una constante epifora que molestaba mucho al enfermo.

En otros enfermos tal como el de la Fig. No. 9, cuya enfermedad data de 12 años, y en el que el labio superior está destruído en su totalidad lo mismo que la nariz de la que solo queda su parte ósea, el ojo izquierdo ha sido totalmente invadido por contiguidad de las lesiones nasales, lo mismo que el ojo derecho que tiene ambos pár- 
pados ulcerados. En sus filtimos dlas tuvimos oportunidad de vet a este enfermo: había perdido por completó la visión.

Las lesiones mucósas tèréiàrias, són más profundas, destriyen la úvula, pilàres; amigdalas, transformanto la Anàtomía normal de la garganta; se propagain a la laringe, las cuerdas bucales, sobre todo lás superióres; que están engrosadas y ulceradas; en unos, la epiglotis está casi destruída, de manera que al deglutir los atimentos sufre el enfermo accesos de sofocación, acompañados de tos violenta, síntomas que obligán al enfermo a'reducirlós poco a poco eñ cantidad; la tos es ron ca $y$ frecuentè; con un ruído especial como el que se produce al soplàr un tubo; la voz también és ronica y con dificultad se puede entender lo que el enfermo habla; cási llegan a la afonía; la salivación es abundante y mucho mayor qué en el período secundário. En otrọs, el nódulo blastómićsico asienta én las cucrdas bucales y el enfermo presenta todos los síntomas de la estenosis laringea, tal es el enfermo de la Fig. No. 7, que muri6 víctima de la epidemia de la grippe acaécida en La Paż en 1919.

Es verdaderamente lamentable lä vida de estos enfermos: no püeden dormir, ni comer; cada día la miseria fisiológica va siendo más acentuada; el aliento es un tanto fétido.

En resumen, aspécto pálido de las ulceraciones, recubiertas de un barniz que le da un aspectó plateado; propágación hacia la laringe con destrucción de la epiglotis,- accesos de sofocación, tos ronca y cusi sionía, sallvación intensa, mutilaciones de las más variadas y desnutrición acentuada del organismo, earacterizan el tercer período de la Blastomicósis:

A esta división que nos parece la más: rácional, tanto porque clínicamenté la díferencia es posible èn räzón de la evolución de la enfermedad y del aspecto de la ulcèración, cuanto porque ella contribuye a facillitar su descripción, nos permitimos añadir un cuarto período, en żzón de que hay caracteres que permiten tipifi: carlo.

Cuarto páríodo o beriodo caquectico.-En este período presentan los individuos anemia bien acentuada, caracterizada por la decoloración de lás mucosas; el enflaquecimienta es intenso, hay pérdida dicl apetito; este período casi lo pasán en cama, son atacados de diarrea intensa, que no cede a los astringentes, ni al opie; este período llega después de 10,12,14 o más años de enfermedad, cuảndó el en îermo está esquelétizado en vida: La tos y la dísné, son los últimos fenómenos de estos desgraciados que por lo gerreral fueron i víctimás de la ènfermédad en los más lozanos días de "su juventud: 

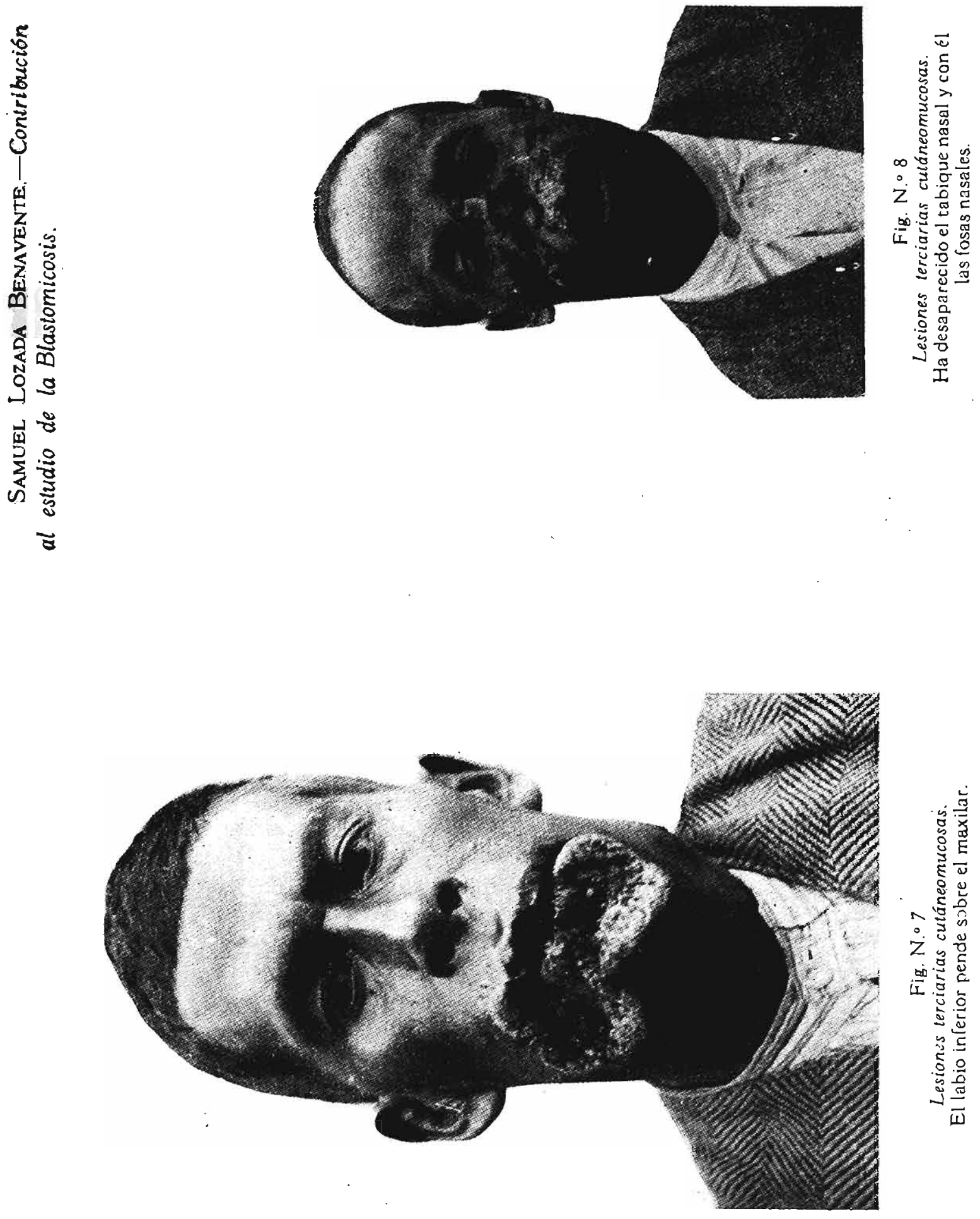

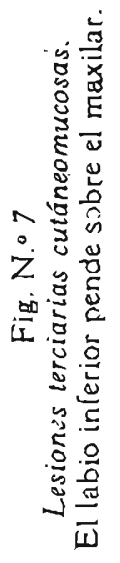


Samuel Lozada Benavente.-Contribución al estudio de la Blastomicosis.

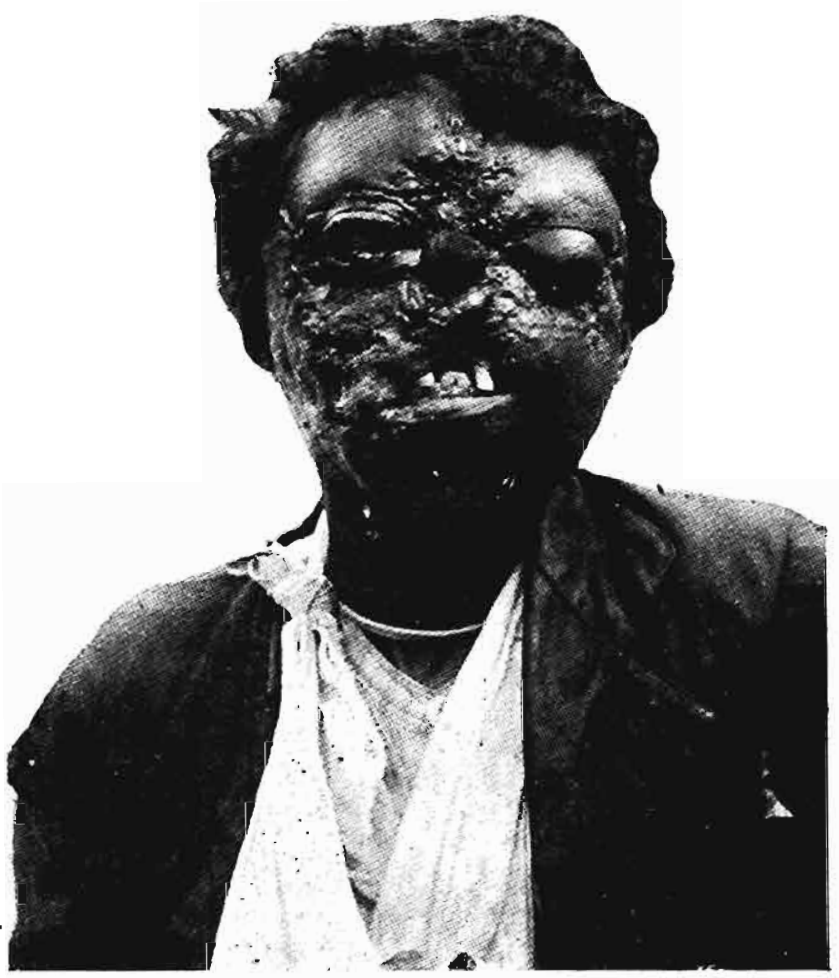

Fig. N.o9

Lesiones lerciarias cutáneomucosas.

Ectropión del párpado inferior derecho y pérdida consecutiva de la visión. 


\section{Agente causal}

El agente causal de la Blastomicosis es un blastomiceto hasta thoy no clasificado perfectamente, que pertenece a la familia de los hongos; fúe descubierto por primera vez en el Perú por Escomel, en enfermos venidos de regiones montañosas del.Perú y Bolivia.

Acostumbrado a ver en el laboratorio de mi maestro, el Dr. EsCOMEL, los procedimientos que emplea para hacer el exámen de las: leishmanias y blastomicetos y de haber visto los cultivos de este último en zanahoria, arracacha, patatas, etc., me dirijí a La Paz; donde me encontré en el Lazareto de dicha ciudad, con enfermos de esta clase y en los que pude desde mi llegada, descubrir en las preparaciones microsc6́picas, hechas con el raspado superficial, un blastomiceto de forma ovalada, junto con otros gérmenes de infección secundaria; debo declarar que esta clase de exámenes no hubiera podido llevarlos a cabo sin la amabilidad del ilustre médico boliviano, el Dr. Nestor Morales Villazon, quien galantemente me brindó el Instituto de su dirección, lo mismo que la colaboración del inteligente joven; el Sr. Llanos.

Coloreando nuestras preparaciones según el método de Gram se observaba un hongo de forma ovalada, muchas veces de grandes dimensiones. En los cultivos que hicimos con el producto superficial de lás ulceraciones, empleando el medio de Saboureau (gelosa, peptona y glucosa), se desarrollaban a la temperatura del laboratorio, después de 48 y 56 horas, colonias micósicas que caracterizamos con el Sr. Llanos, después de siembras repetidas.

Coloración.-La coloración que hëmos empleado es la de' Giem sa, previa fijación por el alcohol-eter; con ella el protoplasma se. tiñe en azul y la masas cromáticas en rojo, las vacuolas quedan claras, *por lo demás también se coloran por el Kuhne, presentándose en color azul muy obscuro, casi negro, las masitas cromáticas; por ZiẹtGabbet, los cuerpos protoplasmáticos se coloran en rosa morado en tanto que las masas cromáticas se tiñen en purpura; la tionina fenicada, el violeta de genciana, los colora fuertemente, lo mismo que el:método de Klausner».

Medios de cultivo-En el agua glucosada, el hongo se desarrolla a las 24 horas; lo mismo en agua sacarosada, en leche, en oca, en arracacha, en camote, en zanahoria, en patata, en el medio de Saboureau, etc.,

No entramos è ámplios detalles acerca de estè punto, porque no. nos ha sido posible hacer estudios especiales. LUT2, y SPLENDORE en el Brasil, Escomel en el Perú, Morales Villazon en Bo. 
livia, se han ocupado con amplios detalles de la cuestión, llegando este último ha hacer verdadera selección de razas.

\section{Anatomia patologica}

Al lazareto de La Paz, procedente de la regiones de Yungas, vino un enfermo atacado de Blastomicosis en quien el exámen microscópico reveló la existencia de blastomicetos en el raspado de sus ulceraciones; este enfermo que estaba en el tercer período de su enfermedad, después de una evolución de 14 años, se ahorcó con una sábana a los pocos días de su llegada, dándonos oportunidad para constataciones autópsicas. El exámen anatomopatoscópico del árbol aereo-digestivo, reveló que el volúmen de las glándulas salivares, en especial las submaxilares, era mayor que el normal; en la garganta había una amplia ulceración botonosa, surcada en diferentes direcciones, que comprendía la úvula, amígdalas, pilares, velo del paladar, etc. La epiglotis estaba casi destruída, quedando sólo un muñón considerablemente engrosado y botonoso, el cual carecía de flexibilidad; el repliegue gloso-epiglótico era el asiento de una ulceración dividida por surcos que separaban pequeños nódulos; las cuerdas bucales superiores estaban casi destruídas; los repliegues ariteno-epiglóticos eran asiento de ulceraciones y de tejidos engrosados, con todos los caracteres de las ulceraciones que hemos descrito; la mucosa traqueo-bronquial, a partir de las cuerdas bucales inferiores, estaba completamente sana. Por su parte anterior se notaba el tiroides hipertrofiado; pero al exámen visual fuera de la hipertrofia no había nada de anormal; los pulmones completamente sanos; tales fueron las lesiones del mencionado enfermo, cuya laringe está en las Figs. 10 y 11.

La epidemia de grippe que tuvo lugar en La Paz en julio de 1919, hizo sus víctimas entre algunos enfermos que tratábamos en los que hicimos las autopsias. Describiremos uno de estos enfermos, que estaba en pleno período de cicatrización: siguiendo el método de evisceración total encontramos que las glándulas sub-maxilares y parótidas tenía mayor volumen que el normal; la bóveda palatina presentaba grandes extensiones de tejido cicatricial, pero todavía existlan ulceraciones; la epiglotis estaba bastante engrosada y algo deforme, había perdido considerablemente su elasticidad, era casi rígida y como pegada a la base de la lengua, en su base existían do grandes nódulos y uno de menores dimensiones y al tacto tenía una consistencia seini-dura; las cuerdas bucales superiores estaban engrosadas y en pleno período de ulceración, las inferiores estaban reemplazadas por un tejido fibroso, cicatricial, de color blanque 
Samuel lozada Benavente.-Contribución al estudio de la Blastomicosis.

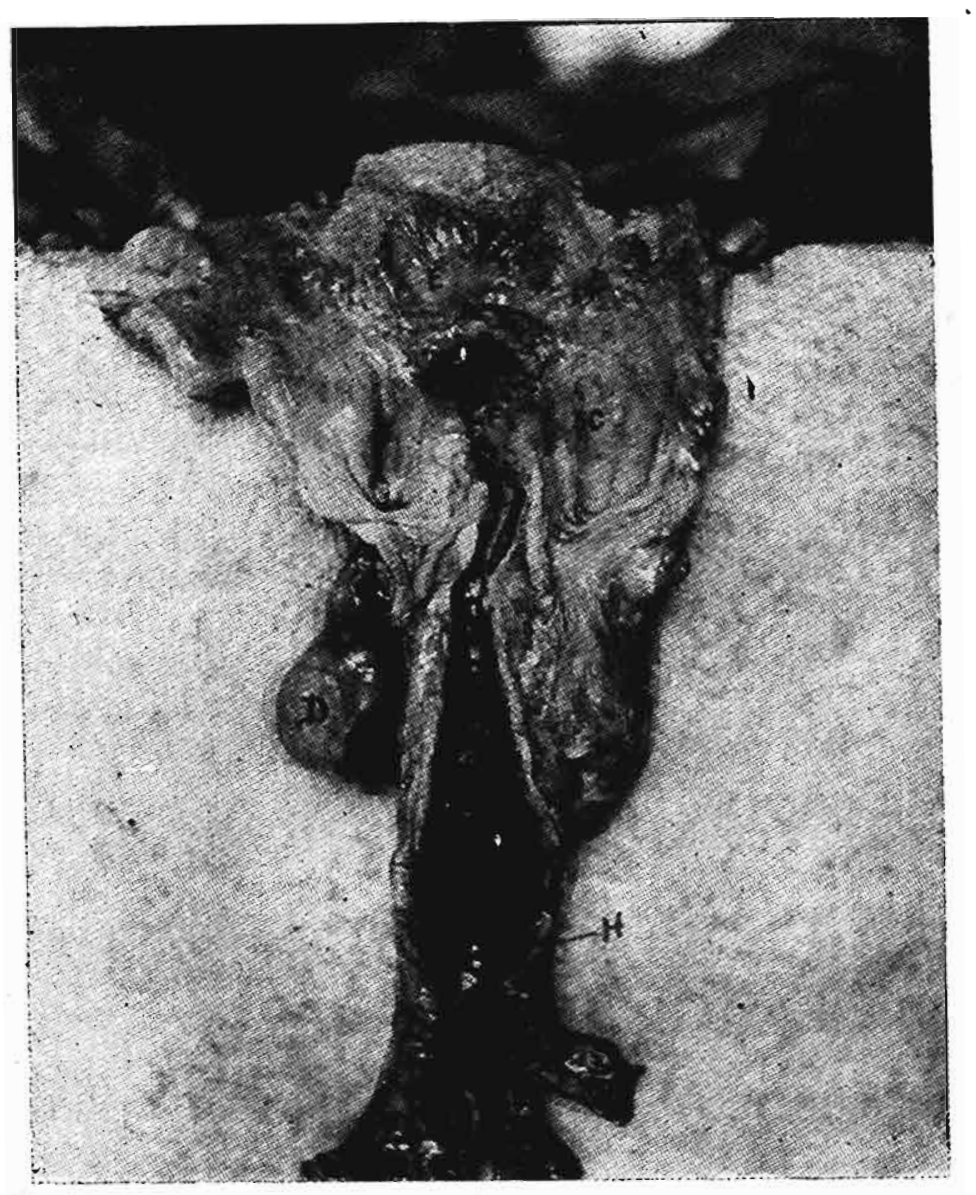

Fig. N. * 10

Arbol laríngotraqueal con lesiones blastamlcosicas visto por su cara posterior.

A.-Repliegue glosoepiglotico ulcerado.

B. - Epiglotis ulcerada y convertida en un murón muy infiltrado.

C.-Repliegue glosoepigl6tico ulcerado.

D.-Cara posterior del lóbulo izquierdo del tiroides.

E.-Cara posterlor de la lengua.

F.-Cuerdas bucales superiores ulceradas e infiltradas.

H.-Cara mucosa de la traquea. 
Samuel lozada Benavente.-Contribución al estudio de la Blastomicosis.

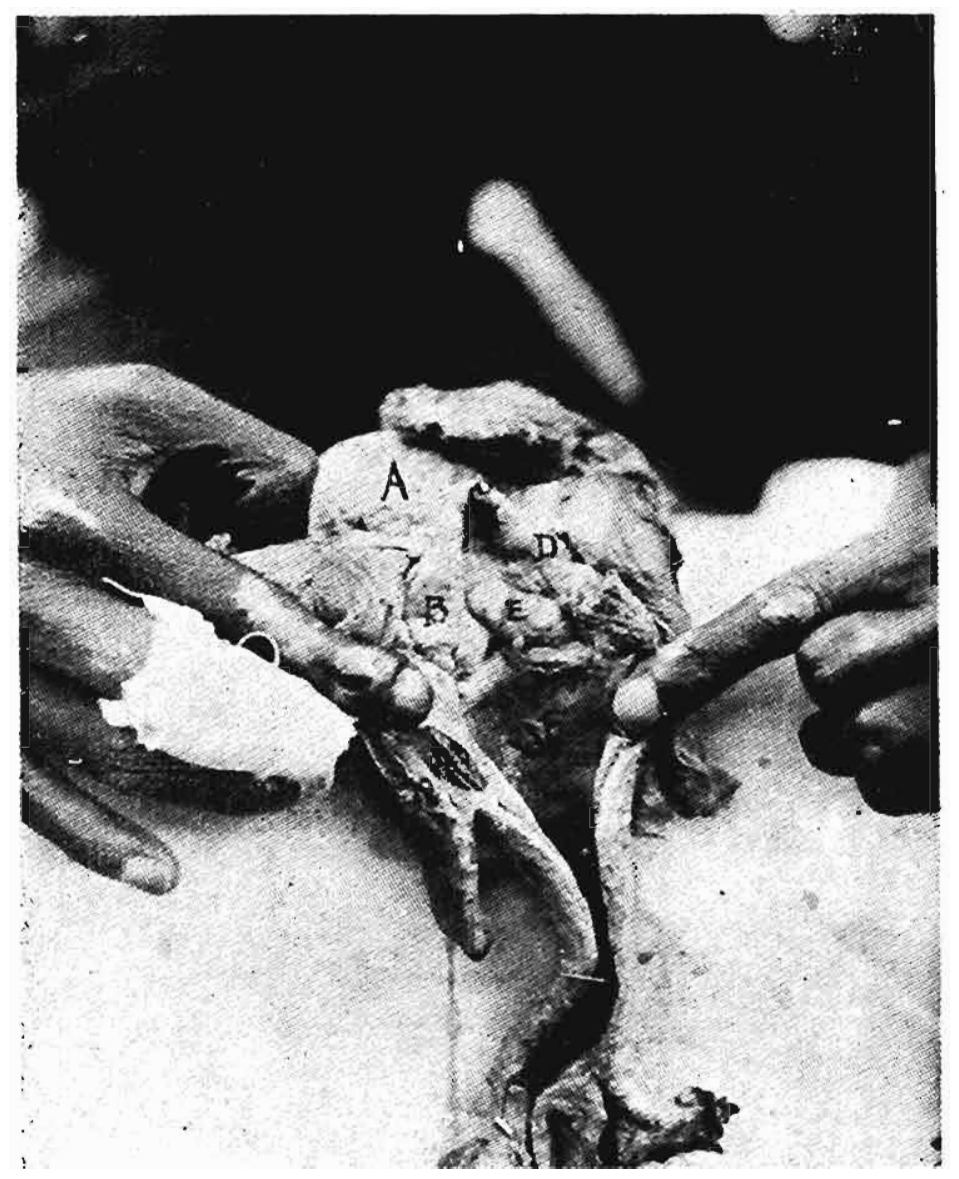

Fig. N.o 12 .

Arbol laríngolraqueal con lesiones blastomicbsicas visto por su cara posterior.

A. - Parte posterior de la lengua.

B.-Repliegue glosofaringeo invadido por una ulceración blascomicósica.

C.-Fpiglocis infiltrada.

D. - Repliegues aritenoepiglóticos invadidos por el proceso ulceroso.

E.-Nódulos blastomicosicos.

F.- Herida de la mucosa traqueal, por fractura de un cartílago. 
cino, notándose en algunos puntos verdaderas zonas de retracción; los repliegues ariteno-epiglóticos estaban engrosados y formando parte del proceso ulcerativo; el orificio glótico desmesuradamente ensanchado y de un diámetro mayor que el normal; el resto del árbol traqueo-bronquial congestionado por el proceso bronco-neumbnico de que fué víctima el individuo, pero indemne de lesiones blastomicósicas. Las piezas anatomo-patológicas se encuentran en el Museo de Anatomía Patológica y Bacteriología de La Paz; la laringe de este enfermo que ofrecía lesiones del período terciario, despés de 11 años de enfermedad, está representada por la Fig. No. 12 .

Por las numerosas autopsias que hemos hecho a esta clase de enfermos, en sus diferentes períodos de evolución, estamos convencidos que las lesiones blastomicósicas nunca pasan más allá de las cuerda bucales inferiores, no llegando ni a la mucosa traqueal y mucho menos a la de los bronquios. El estudio histopatoscópico de las lesiones blastomicósicas ha sido hecho por el Dr. Escomel; no harenmos sino repetir sus constataciones y sus descripciones.

Un nódulo blastomicósico incluído ya sea a la parafina o celoidina, nos dá al corte tres zonas: la zona central parasitaria donde se encuentran abundantes blastomicetos; la segunda zona compuesta de células reaccionales y la tercera zona donde se encuentran las llamadas por su autor, células blastomicósicos, las cuales son células redondas, ovales o poliédricas, con núcleo y nucleolo, notándose algunas veces vacuolas en su protoplasma. Es tan característica la anatomía patológica de esta enfermedad, que sirve por si para caracterizarla, pues, no se encuentran tales formaciones en otras úlceras crónicas, como las leishmaniásicas; a este respecto nos permitimos copiar del trabajo del Dr. Escomel, publicado en los *Anales de la Facultad de Medicina de Montevideo*, lo que sigue: «La presencia del nódulo blastomicósico, con sus tres zonas y la constancia de parásitos es tan característica y única que no puede confundirse con nada, constituyendo un síntoma anatómico, patognomónico, de la afección tropical americana que describimos; no necesitamos decir nada más acerca de la separación de las leishmaniasis, con la que sería posible confundirla».

(Continuará). 